\title{
ИССЛЕДОВАНИЕ МИГРАЦИОННЫХ ПРОЦЕССОВ РЕГИОНОВ РОССИИ НА ПРИМЕРЕ ЦЕНТРАЛЬНОГО ФЕДЕРАЛЬНОГО ОКРУГА
}

\author{
(c) 2021 Трегуб Илона Владимировна \\ доктор экономических наук, профессор департамента математики \\ Финансовый университет при Правительстве Российской Федерации, Россия, Москва \\ E-mail: ilonavl_fa@mail.ru \\ (c) 2021 Комлева Камилла Эриковна \\ студент-бакалавр \\ Финансовый университет при Правительстве Российской Федерации, Россия, Москва \\ E-mail: komlevaker@yandex.ru
}

Предмет. Миграционные процессы в регионах России.

Цели/задачи. Анализ проводится в рамках рассмотрения взаимосвязи между коэффициентом миграции населения в Центральный федеральный округ и социокультурными факторами и экологической ситуацией в регионе.

Методология. Для анализа данных и разработки модели используется методика корреляционнорегрессионного анализа.

Результаты. Исследование проводилось по нескольким направлениям: выявление положительных или отрицательных корреляций между ключевыми факторам модели, определение наличия и значимости взаимосвязи между переменными эконометрической модели, тестирование предпосылок теоремы Гаусса-Маркова для определения свойств коэффициентов линейной регрессии. Данная модель отражает сильное влияние социокультурных факторов на миграцию населения в центральный федеральный округ. Модель пригодна для прогнозирования.

Ключевые слова: Центральный Федеральный округ; миграция населения, экологические факторы, социокультурные факторы.

Введение. Миграция - это пространственное расположение места жительства человека, является центральной темой общества. Данные о международной миграции занимают важное место в статистике народонаселения.

Причины смены места жительства разнообразны. В дополнение к миграции из профессиональных, семейных и образовательных целей, общим мотивом является бегство от угроз или преследования и насилия (поиск защиты). Однако основными причинами миграции населения можно назвать социальные и экономические причины. Согласно многочисленным исследованиям миграции в Российской Федерации за последние 20 лет, разница между бедными и богатыми людьми значительно увеличилась с 2000 года. Кроме того, наблюдается большой разрыв в развитии между центральными регионами и остальной Россией.

В связи с этим население центральных регионов страны растет. Однако интересно выяснить, какие именно факторы вызвали активный приток населения в центральную часть России.
Стоит задача объяснить взаимосвязь между коэффициентом миграционного прироста и количеством зрителей театров, количеством посещений музеев, количеством проданных населению туристических пакетов, выбросами загрязняющих веществ в атмосферный воздух, поступающими из стационарных источников, сбросом загрязненных сточных вод в поверхностные водные объекты в Центральном федеральном округе.

Для этой цели были взяты данные за 16 лет с 2005 по 2020 год с использованием статистических данных из российских источников.

Основной целью данной работы является изучение факторов, влияющих на эконометрическую модель. Более того, найдите условия, при которых модель определяется как адекватная. После этого анализа конечной точкой будет прогноз будущих эконометрических переменных в исследуемом регионе.

Основная проблема миграции в Центральный федеральный округ - перенасыщенность региона, плохая экология, недостаток ин- 
фраструктуры и места для проживания, а для остальных регионов это может угрожать большим неосвоенным территориям с большим потенциалом. Кроме того, это может показать, на чем правительствам других регионов России необходимо сосредоточиться, чтобы уменьшить значительный прирост в Центральном федеральном округе и разгрузить центр страны.

\section{Обзор современного состояния изучае- мой проблемы}

Для составления модели и подбора наиболее значимых показателей необходимо было провести анализ предыдущих исследований. Прошлые исследования в значительной степени касались видов негативного воздействия на миграцию населения. Исследования показали, что правительства разных стран были готовы изменить экологическое законодательство и ограничения загрязнения, чтобы привлечь мигрантов. На уровень загрязнения влияет уровень образования (люди с более высоким уровнем образования чаще думают о качестве воды и воздуха и стремятся улучшить свое положение), семей- ное положение (разведенные люди и люди без детей меньше заботятся об окружающей среде; согласно исследованию, это связано с тем, что семейные люди думают о будущем своих детей, их здоровье и благополучии).

Говоря о миграции в России, ученые учитывают основные показатели для России, такие как численность населения, возраст и численность трудоспособного населения, рынок труда и уровень жизни, рынок жилья, здравоохранение, образование, инфраструктура, экология и культура.

Однако, в последнее время активно исследуются социальные и культурные факторы, потому что они подразумевают под собой уровень доходов, условия проживания, образованность населения. Поэтому в модели будут рассмотрены посещения музеев, театров, покупка турпутёвок и загрязнение воздуха и воды.

Анализ влияния факторов на коэффициент миграции. Моделирование миграционных процессов основано на статистических данных, собранных из открытых источников. Данные представлены в таблице 1.

Таблица 1. Статистические данные.

\begin{tabular}{|c|c|c|c|c|c|c|}
\hline & Km & Th & Mus & Tur & Em & Dis \\
\hline $\mathbf{2 0 0 5}$ & 101.0 & 23.2 & 62.7 & 74.5 & 149.6 & 434.1 \\
\hline $\mathbf{2 0 0 6}$ & 94.0 & 23.9 & 65.0 & 75.0 & 157.0 & 418.6 \\
\hline $\mathbf{2 0 0 7}$ & 70.0 & 25.1 & 63.8 & 86.6 & 158.8 & 387.0 \\
\hline $\mathbf{2 0 0 8}$ & 69.8 & 27.5 & 68.8 & 111.9 & 158.8 & 379.8 \\
\hline $\mathbf{2 0 0 9}$ & 64.1 & 26.7 & 65.7 & 146.4 & 157.7 & 359.6 \\
\hline $\mathbf{2 0 1 0}$ & 74.0 & 26.2 & 64.7 & 165.1 & 161.8 & 376.1 \\
\hline $\mathbf{2 0 1 1}$ & 56.0 & 27.9 & 72.7 & 139.3 & 159.8 & 361.3 \\
\hline $\mathbf{2 0 1 2}$ & 62.0 & 29.8 & 76.0 & 152.1 & 159.0 & 365.1 \\
\hline $\mathbf{2 0 1 3}$ & 60.0 & 31.1 & 82.3 & 161.2 & 157.0 & 357.0 \\
\hline $\mathbf{2 0 1 4}$ & 56.0 & 31.7 & 88.3 & 149.9 & 155.3 & 332.8 \\
\hline $\mathbf{2 0 1 5}$ & 57.0 & 31.9 & 111.1 & 144.6 & 153.1 & 320.3 \\
\hline $\mathbf{2 0 1 6}$ & 45.0 & 33.4 & 114.0 & 92.7 & 155.9 & 318.7 \\
\hline $\mathbf{2 0 1 7}$ & 51.0 & 33.3 & 97.7 & 150.3 & 154.6 & 314.3 \\
\hline $\mathbf{2 0 1 8}$ & 47.0 & 34.4 & 92.5 & 152.5 & 152.9 & 303.3 \\
\hline $\mathbf{2 0 1 9}$ & 47.0 & 32.7 & 113.3 & 222.8 & 160.3 & 287.9 \\
\hline $\mathbf{2 0 2 0}$ & 17.0 & 13.3 & 37.8 & 74.3 & 110.1 & 201.3 \\
\hline
\end{tabular}

Источник: Росстат

Составлено авторами

В таблице введены следующие обозначения:

Кm - Коэффициент миграционного прироста на 10000 человек населения;

$\mathrm{Th}$ - Количество зрителей театров на 100 человек населения;

Mus - Количество посещений музеев на 100 человек населения;

Tur - Количество туристических пакетов, проданных населению, десять тысяч;

$\mathrm{Em}$ - Выбросы загрязняющих веществ в атмосферный воздух, поступающие от стационарных источников (десять тысяч тонн);

Dis - Сброс загрязненных сточных вод в поверхностные водные объекты (10 миллионов кубометров). 
Динамика показателя коэффициент миграционного прироста представлена на рисунке 1.

Из рисунка 1 видно, что коэффициент миграции снижается на протяжении этого времени, однако снижение было неравномерным. В 2012 и 2015 годах происходило незначительное увеличение коэффициента миграции в центральном федеральном округе. В 2016 году миграция снизилась из-за последствий валютного кризиса в связи с событиями на Украине. В 2011 году сказались последствия финансово-экономического кризиса 2008-2010 годов. В 2020 году коэффициент миграции снизился в 3,5 раза из-за пандемии коронавируса, локдауна и затруднения перемещений людей.

Предварительный анализ данных осуществлялся путем расчета коэффициентов парной корреляции, которые позволяют обнаружить линейную связь между исследуемыми факторами. Матрица парных коэффициентов корреляции представляет собой матрицу, элементами которой являются парные коэффициенты корреляции всех факторов модели. Результаты расчета элементов матрицы парных корреляций для переменных, характеризующих миграционные процессы в ЦФО представлены в таблице 2.

Согласно результатам, представленным в таблице 2 , можно отметить, что существует положительная линейная связь различной силы между коэффициентом миграционного прироста и следующими экзогенными переменными:

- выбросами загрязняющих веществ в атмосферный воздух, поступающими из стационарных источников (соответствующий коэффициент корреляции равен $\rho=0,87$, сильная связь);

- сбросом загрязненных сточных вод в поверхностные водные объекты ( $\rho=0,95$, сильная связь);
- количеством зрителей в театрах $(\rho=0,56$, связь средней силы);

- количеством туристических пакетов, проданных населению ( $\rho=0,57$, связь средней силы);

Слабая положительная линейная корреляция обнаружена между коэффициентом миграционного прироста и количеством посещений музеев.

Для разработки эконометрической модели был использован регрессионный анализ.

Спецификация модели имеет вид:

$$
\left\{\begin{array}{c}
\mathrm{Km}_{\mathrm{t}}=\mathrm{a}+\mathrm{b} \cdot \mathrm{Th}_{\mathrm{t}}+\mathrm{c} \cdot \mathrm{Mus}_{\mathrm{t}}+\mathrm{d} \cdot \mathrm{Tur}_{\mathrm{t}}+\mathrm{k} \cdot \mathrm{Em}_{\mathrm{t}}+\mathrm{m} \cdot \mathrm{Dis}_{\mathrm{t}}+\varepsilon_{\mathrm{t}} \\
\mathrm{E}\left(\varepsilon_{\mathrm{t}}\right)=0 \\
\mathrm{D}\left(\varepsilon_{\mathrm{t}}\right)=\sigma^{2}
\end{array}\right.
$$

где a, b, c, d, k, m - параметры модели, $\varepsilon_{t}-$ случайное возмущение. При составлении спецификации модели были наложены ограничения на случайное возмущение: математическое ожидание $\varepsilon_{t}$ предполагается равным нулю (первая предпосылка теоремы Гаусса-Маркова), дисперсия $\varepsilon_{t}$ постоянна (вторая предпосылка теоремы Гаусса-Маркова).

Коэффициенты модели были оценены методом наименьших квадратов в пакете анализа Excel. Результаты представлены в таблице 3.

Близкое к единице значение нормированного коэффициента детерминации позволяет сделать вывод о том, что 89\% изменений эндогенной переменной объясняются набором экзогенных переменных с помощью модели линейной регрессии, то есть $89 \%$ изменений в количестве посетителей театра, проданных билетов, посетителей музеев, загрязнении воздуха и воды в рамках модели линейной регрессии объясняют миграцию населения в ЦФО.

Проверка значимости коэффициентов модели линейной регрессии была проведена с ис-

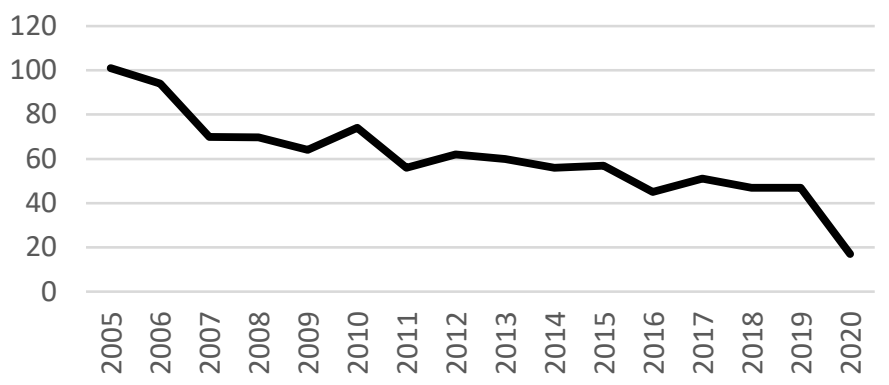

Рис.1. Динамика коэффициента миграции Источник: Составлено авторами 
Таблица 2. Матрица парных корреляций

\begin{tabular}{|c|c|c|c|c|c|c|}
\hline & Km & Th & Mus & Tur & Em & Dis \\
\hline Km & 1.00 & & & & & \\
\hline Th & 0.56 & 1.00 & & & & \\
\hline Mus & 0.27 & $\mathbf{0 . 8 7}$ & 1.00 & & & \\
\hline Tur & 0.57 & 0.54 & 0.42 & 1.00 & & \\
\hline Em & 0.87 & $\mathbf{0 . 8 2}$ & 0.60 & 0.67 & 1.00 & \\
\hline Dis & 0.95 & 0.53 & 0.21 & 0.41 & $\mathbf{0 . 8 6}$ & 1.00 \\
\hline
\end{tabular}

Составлено авторами

Таблица 3. Результаты регрессионного анализа

\begin{tabular}{|l|c|}
\hline \multicolumn{2}{|c|}{ Regression Statistics } \\
\hline Multiple R & 0.97 \\
\hline R Square & 0.93 \\
\hline Adjusted R Square & $\mathbf{0 . 8 9}$ \\
\hline Standard Error & 4.37 \\
\hline Observations & 14.00 \\
\hline
\end{tabular}

Таблица 4. Результаты теста значимости

\begin{tabular}{|c|c|}
\hline Параметр при переменной & P-value \\
\hline Пересечение & 0.14 \\
\hline Th & 0.05 \\
\hline Mus & 0.08 \\
\hline Tur & 0.05 \\
\hline Em & 0.04 \\
\hline Dis & 0.01 \\
\hline
\end{tabular}

пользованием t-теста. Значимость $\mathrm{t}$-статистики приведена в таблице 4. Согласно тесту, все переменные модели являются значимыми при 5\% вероятности ошибки, а фактор «посещение музеев» значим при $10 \%$.

Чтобы проверить адекватность модели, был построен доверительный интервал. В таблице 5 приведены теоретическое и реальное значение зависимой переменной, а также границы доверительного интервала.

Реальное значение попадает в доверительный интервал, следовательно, модель можно признать адекватной и пригодной для прогнозирования.

Оцененная эконометрическая модель имеет вид:

$\left\{\mathrm{Km}_{\mathrm{t}}=227,2-2,51 \cdot \mathrm{Th}_{\mathrm{t}}+0,32 \cdot \mathrm{Mus}_{\mathrm{t}}+0,13 \cdot \mathrm{Tur}_{\mathrm{t}}-1,75 \cdot \mathrm{Em}_{\mathrm{t}}+0,4 \cdot \mathrm{Dis}_{\mathrm{t}}\right.$ $\mathrm{R}^{2}=0.89$
Ошибка аппроксимации модели составила всего 2\%, что говорит о высокой точности использования модели

Согласно результатам теста ГольфельдаКванта (таблица 6), вторая предпосылка теоремы Гаусса-Маркова о гомоскедастичности остатков модели выполняется.

Тест Дарбина - Уотсона на проверку автокорреляции первого порядка, в котором расчетное значение константы оказалось равным $\mathrm{DW}=2.12$, показывает отсутствие автокорреляции (Таблица 7).

Согласно проведённому тесту, остатки модели неавтокоррелированы, поскольку значение лежит в промежутке от du до 4-du. 
Таблица 5. Проверка адекватности модели

\begin{tabular}{|c|c|}
\hline $\mathrm{Y}_{2019}$ & 108.33 \\
\hline $\mathrm{T}_{\text {crit }}$ & 2.78 \\
\hline Нижняя граница & 80.76 \\
\hline Верхняя граница & 125.18 \\
\hline $\mathrm{Y}_{\text {real }}$ & 101.00 \\
\hline
\end{tabular}

Таблица 6. Тест Гольфельда -Кванта

\begin{tabular}{|c|c|}
\hline $\mathrm{F}_{\text {critical GQ }}$ & 19.00 \\
\hline $\mathrm{GQ}_{\text {test }}<\mathrm{F}_{\text {critical GQ }}$ & $1.07<19$ \\
\hline $1 / \mathrm{GQ}_{\text {test }}<\mathrm{F}_{\text {critical GQ }}$ & $0.93<19$ \\
\hline
\end{tabular}

Таблица 7. Тест Гольфрида-Кванта

\begin{tabular}{|c|c|c|c|c|c|c|}
\hline & $\begin{array}{c}\text { Левая } \\
\text { граница }\end{array}$ & & Середина & & & $\begin{array}{c}\text { Правая } \\
\text { граница }\end{array}$ \\
\hline 0 & $\mathrm{dl}$ & $\mathrm{du}$ & 2 & $4-\mathrm{du}$ & $4-\mathrm{dl}$ & 4 \\
\hline 0 & 0.505 & 1.704 & 2 & 2.296 & 3.495 & 4 \\
\hline
\end{tabular}

Оцененные коэффициенты модели состоятельны, эффективны и несмещены. Модель обладает высокой объясняющей способностью и малой ошибкой аппроксимации.

Разработанная модель позволяет количественно оценить степень влияния социокультурных факторов на миграционные потоки. Увеличение притока приезжающих на постоянное место жительства в ЦФО основывается в большей степени на возможность посещения музеев и в меньшей степени на посещение театров. Широкий спектр туристических услуг оказывает положительное влияние на увеличение миграционных потоков. С увеличением количества туристических путёвок для населения коэффициент миграции увеличивается на 0,13 . Это связано с большим количеством рейсов из городов центрального федерального округа и большим выбором мест для посещения.

Экология является важным фактором миграции населения, а центральные регионы ассоциируются у населения с плохой экологией и сильно загрязнённым воздухом. При увеличении выбросов загрязняющих веществ в атмос- ферный воздух, поступающих от стационарных источников, коэффициент миграции снижается на 1,75 . Вместе с тем, загрязнение воды уходит в оценке на второй план из-за небольшой огласки в СМИ и лучшим качеством очистных сооружений.

Вывод. В данной статье были проанализированы основные социальные и культурные факторы, которые могут повлиять на миграцию населения в Центральном Федеральном округе.

В ходе проведенного исследования были выявлены значимые социокультурные и экологические факторы, оказывающие существенное влияние на миграционные процессы. К числу таких переменных относятся посещение театров и музеев, купленные турпакеты, выбросы загрязняющих веществ в атмосферный воздух, сброс загрязненных сточных вод в поверхностные водные объекты.

Исследование показало, что развитая культурная среда, туристические сервисы и благополучное экологическое окружение ЦФО играет положительную роль в притоке населения в округ.

\section{Библиографический список}

1. Антосик Л.В., ИвашинаН.В. Моделирование пространственной зависимости миграционных потоков выпускников вузов Российской Федерации// Прикладная эконометрика. 2019. № 54. С.70-89.

2. Джурко Н.Г. Моделирование межрегиональной миграции в контексте гравитационных аналогий// Институт экономических исследований ДВО РАН.2018. № 2. С.75-85. 
3. Дианов Д. В. Миграция и уровень жизни населения в моделировании экономической безопасности и устойчивого развития// КноРус.2021. № 211. С. 49-78.

4. Кобзева О., Коломоец Е., Лукьянец А., Коротаева Л. Культурные и языковые эффекты миграции: на примере мигрантов и чувашей в республике Башкортостан (Россия)// Журнал этнокультурных исследований. 2021. № 24. с.134-148.

5. Латынина Н.А., Латынин Д. А. Анализ и оценка влияния миграции в Российской Федерации на ВВП и безработицу// Инновационная экономика: перспективы развития и совершенствования.2018. № 31. С.63-75.

6. Мкртчян Н.В. Проблемы в статистике внутрироссийской миграции, вызванные изменением методологии учета в 2011 году// Демографическое обозрение. 2020. № 7. с.83-99.

7. Островская Е.А., Мамонтов Д. С., Спиридонов К.А., Леви И.В. Анализ межрегиональных миграционных потоков в России в проекции отдельных видов миграции// Журнал Новой экономической ассоциации. 2021. № 2. с.36-55.

8. Трегуб И. В. Математические модели динамики экономических систем. - М.: Русайнс. 2018.120 с.

9. Трегуб И. В. Методы визуализации модельных исследований. Saarbrucken, 2013.

10. Tregub I. V. Econometrics. Model of a real system. M. 2016. p.164.

11. Трегуб И.В., Трегуб А.В. Методы анализа и планирования экономической динамики. М.: Кнорус. 2021.186 с. 